Bull. Iraq nat. Hist. Mus.

(2020) 16 (2): 161-172.

https://doi.org/10.26842/binhm.7.2020.16.2.0161

\title{
MONITORING OF THE WILD MAMMAL FAUNA IN BAMO \\ MOUNTAIN IN NORTHERN IRAQ (KURDISTAN) FOR THE FIRST \\ TIME USING CAMERA TRAP METHOD AND RAISING AWARENESS FOR ITS CONSERVATION
}

\author{
Soran H. Ahmed and Soma I. Majeed \\ Department of Biology, College of Science, University of Sulaimani, \\ Sulaimani, Iraq \\ Corresponding author e-mail: soran.ahmed@univsul.edu.iq \\ Received Date: 21 July 2020, Accepted Date: 19 September 2020, Published Date: 21 December 2020
}

\section{ABSTRACT}

Mammals are under threat worldwide due to deforestation, hunting, and other human activities. In Iraq, a total of 93 species of wild mammals have been recorded including species with global conservation concern. Bamo Mountain is situated within the Zagros Mountains in northern Iraq which is a suitable habitat for wild mammals. Due to scarcity of the field survey efforts and cryptic behavior, monitoring of the wild mammals fauna in Zagros Mountain seems challenging. Therefore, we used a camera trap which seems to be an ideal way to determine species diversity of wild mammals in Bamo Mountain. Moreover, interviews with local villagers were performed. The mammalian diversity of Bamo Mountain is not fully explored but seemed threatened by local extinction due to poaching and wildlife trafficking, minefields, and annual fires.

In this study, a total of eight species of wild mammals were recorded for the first time in Bamo Mountain using camera trap method including the Persian leopard Panthera pardus saxicolor Pocock, 1927, and the wild goat Capra aegagrus Erxleben, 1777, flagship and key species of conservation concern. As far as it is concerned, the major threats on the wild mammals were discussed and some important points were highlighted towards the establishment of the protected area in Bamo Mountain.

Keywords: Fauna of Iraq, Key species, Persian leopard, Protected areas, Sustainable management.

\section{INTRODUCTION}

Wild mammals are under threat worldwide; risks to terrestrial species are mainly from modifications and loss of their habitats, and sometimes from hunting randomly, illegally, or commercially (Bowyer et al., 2019). A total of 93 species of wild mammals have been recorded in Iraq and belonging to eight orders, 28 families, and 65 genera. The mammalian species were evaluated by the International Union for Conservation of Nature and Natural Resources (IUCN) as one listed as Extinct, another as Critically Endangered, four species as 
Endangered, eight as Vulnerable, seven as Near Threatened, and three as Data Deficient (AlSheikhly et al., 2015). Major threat to the wild animals in Iraq include land utilization by humans for agriculture, road construction, deforestation, illegal hunting and minefields in the northeastern borders with Iran, which represent major hazards for humans and wildlife including threatened species such as Persian leopard and wild goat (Nature Iraq and Iraqi Ministry of Environment, 2011; Al-Sheikhly et al., 2020).The conservation of wild mammals is vital and can be achieved through collecting information on the species diversity and distribution in various forest conditions. However, in tropical forest habitats it is extremely difficult to observe wild animals because they are elusive, prefer dense vegetation, occur in low numbers, keep distance with humans, and mostly are nocturnal (Debata and Swain, 2018). In this regard, camera traps which have been broadly used by wildlife researchers are the best way to identify the fauna species presented in the particular region; it can also be used for investigating patterns of activities and species abundance (Yasuda, 2004).

The mammalian fauna of northern Iraq (Kurdistan) is divers and naturally connected to the zoogeographic realm of western Iran, a territory stretching mainly along the northeastern and eastern mountains and foothill landscapes adjacent to the borders with Iran. However, the status of many mammalian species is not fully known. Eight restricted-range species are found in the forested mountains, rocky valleys, and grassy steppes of this region: the Iranian wolf Canis lupus pallipe Sykes, 1831 the Persian leopard Panthera pardus saxicolor Pocock, 1927 , the Iranian (Asiatic) cheetah Acinonyx jubatus venaticus Griffith, 1821, the Persian goitred gazelle Gazella subgutturosa subgutturosa Güldenstädt, 1780, the wild goat Capra aegagrus Erxleben, 1777, the Persian squirrel Sciurus anomalusGmelin, 1778, the Persian jird Meriones (Parameriones) persicus Blanford, 1875, and the Persian water vole Arvicola amphibius persicus Linnaeus, 1758 (Al-Sheikhly et al., 2015).

The abundance and distribution of chiropteran and rodent species is not fully discovered; a total of eight bats and 13 rodents were recorded from northern Iraq; however, further surveys may reveal additional records (Al-Sheikhly et al., 2015). Furthermore, the mountains of northern Iraq are refugees of many species of carnivores such as Grey Wolf, Asiatic jackal Canis aureus Linnaeus, 1758, Red fox Vulpes vulpes Linnaeus, 1758, Stone martin Martes foina Erxleben, 1777, Marbled polecat Vormela peregusna Güldenstädt, 1770, Least weasel Mustela nivalis Linnaeus, 1766, Middle East badger Meles canescens Blanford, 1875, Eurasian otter Lutra lutra Linnaeus, 1758, Small asian mongoose Herpestes javanicus É. Geoffroy Saint-Hilaire, 1818, Indian grey mongoose Herpestes edwardsi É. Geoffroy SaintHilaire, 1818, Brown bear Ursus arctos Linnaeus, 1758 , Striped hyena Hyaena hyaenaLinnaeus, 1758, wild cat Felis silvestris Schreber, 1777, Jungle cat Felis chausSchreber, 1777, and Eurasian lynx Lynx lynx Linnaeus, 1758 which those status and current distribution range requires further investigation (Harrison and Bates, 1991; AlSheikhly and Haba, 2014).

Bamo Mountain is a highly diverse area and a remarkable refugee for wildlife; however its wild mammal fauna is under real threats. Due to these significant threat impacts, it can be predicted that the distribution and population size of many wild mammalian species might have been negatively affected, depleted, or in fact could have already been extinct. Unfortunately, the lack of systematic field survey and sufficient data make the determination the current status of the wild mammal fauna in Bamo Mountain virtually impossible. In this 
study, we carried out a camera trap survey in two areas in Bamo Mountain combined with interviews with local people in order to estimate the species diversity, raising awareness among local communities, and understanding the different threat impacts facing the native wild mammal fauna. Our efforts will be useful in providing some preliminary data to opening a gate for further researches and formulating appropriate management and conservation strategies.

\section{Study area}

\section{MATERIALS AND METHODS}

Bamo Mountain ( $\left.34^{\circ} 54^{\prime} 14.0^{\prime \prime} \mathrm{N} 45^{\circ} 44^{\prime} 16.4^{\prime \prime} \mathrm{E}\right)$ is part of the Zagros Mountains fold belt that extends from northeastern Turkey through northern Iraq and down to western and southwestern Iran. It is located $17 \mathrm{Km}$ to the east of Darbandikhan city in Sulaymaniyah Province in northern Iraq (Kurdistan). It is a transboundary monotonic mountainous habitat which consists mainly of rocky cliff and mountain slopes with deciduous forests dominated by oak plants and stretching the northeastern borders with Iran. The entire area size is about $115 \mathrm{Km}^{2}$ and, its top elevation is 1,841 meters a. s. 1 . Due to limitation of camera traps used and not-cleared active minefields from Iraq-Iran War, only a small section of this mountain has been surveyed (Map 1).

\section{Camera trap survey}

The camera trap survey method is used in this study (Sutherland, 2006). We set one camera trap (Stealth Cam -6.0 megapixel P12 50ft Scouting Camera model) in two different locations over two collective survey periods (2017 and 2019). In order to increase detecting probability and obtain more video footages with a very limited number of camera traps, we fixed our camera trap on the main roads between rocky cliffs which may be used by the wild mammals especially those suspected to searching for foods, patrolling marking their territories, and performing other activities. We had not used any kind of baits in our study. Despite the vastness of our study area compared to our surveying efforts, our camera trap had captured significant footages of different mammalian species during our observations.

The first period of camera trap survey started from 30 March to 15 April 2017. Our camera trap was set on a rocky cliff in Bamo Mountain (34 $56^{\prime} 15^{\prime}$ 'N $45^{\circ} 46^{\prime} 17^{\prime}$ ' $\mathrm{E}$ ) elevation is 1,558 $\mathrm{m}$ a. s. 1 .. At the end of the first survey period, the camera trap had checked for data collecting and battery replacement; it was reseated to obtain additional video records at the same place afterward. In 5 May 2017 we checked our camera trap for a second survey period; unfortunately, our camera trap had been stolen by a local hunter and our survey schedule was canceled. Later on, over one year, we reclaimed our camera trap after being confiscated by the Forestry Police from a local hunter, who used it for illegal hunting purposes. The memory card of the confiscated camera trap had been removed; thus we did not obtain any additional data.

The second period of camera trap survey started on 8 October 2019, and our camera trap was set at another place in Bamo Mountain ( $34^{\circ} 56^{\prime} 27^{\prime}$ 'N $\left.45^{\circ} 46^{\prime} 00^{\prime \prime} \mathrm{E}\right), 570 \mathrm{~m}$ a. s. 1 . far from the first site and its elevation was 1,306 meters and the camera trap was retrieved over a month on 8 November 2019. The species identification remarks were noted based on (Harrison and Bates, 1991). 


\section{Interviews}

Besides our major camera trap survey, information on the diversity, abundance, and major threats on the wild mammal fauna in Bamo Mountain were obtained through intensive interviews and personal communications with local villagers, hunters, and shepherds. Interviews were obtained through note taking and reviewing unpublished materials (e.g. hunting photograph, video recordings, and reports) and the reliability of the submitted materials were verified by the authors.

\section{RESULTS AND DISCUSSION}

A total of eight species belonging to 8 genera and 4 orders of terrestrial wild mammals were recorded for the first time in Bamo Mountain (Pl. 1). During the first period of camera trap survey four different species belonging to 4 genera and 3 orders of wild mammals were recorded. The recorded species were: wild boar Sus scrofa Linnaeus, 1758, Indian crested porcupine Hystrix indica Kerr, 1792, Caucasian squirrel and European hare Lepus (Eulagos) europaeus Pallas, 1778. Based on our interviews, these species seem abundant and regularly observed in different habitats within Bamo Mountain. During the second period of the camera trap survey five different species belonging to 5 genera and 3 orders of wild mammals were recorded; which included: Indian crested porcupine, wild goat, Red fox, Golden jackal and Persian leopard.

The Indian crested porcupines were captured more frequently (22 times); the Golden jackal was captured four times; the wild goat was captured twice; the wild boar, European hare, and Red fox were all captured twice. Finally, the Persian leopard and Persian squirrel were captured only once. The majority of the camera trap video footages was recorded at night, $88.88 \%$ and $11.11 \%$ of footages was recorded during day time. Therefore, the camera trap method seems adequate and extremely helpful to detect the nocturnal animals which are hard to see at night. As our results suggest, the temporal distribution of the wild mammals in Bamo Mountain is mainly at night which may be attributed to the diurnal anthropogenic disturbance threats or by other unknown natural factors; thus, further monitoring is required.

One of our main significant observations obtained in our recent investigation is the confirmed occurrence of the Persian leopard for the first time in Bamo Mountain, a new distribution range for this flagship carnivore in northern Iraq (Kurdistan). According to the IUCN Red List, the leopard is listed as Vulnerable (Stein et al., 2020); however, the Persian leopard, Panthera pardus saxicolor is yet not evaluated (Khorozyan, 2016).

Hatt (1959) mentioned that leopards are few and scattered in northern Iraq where only two skins were obtained from Kurdistan Mountains; one from Rawanduz, and the other from and Bradost Mountain. Since then, no further records have been made until 2008 when a Persian leopard was killed near Mandli in Diyala (Al-Sheikhly, 2012) and another was killed by a landmine from Iraq-Iran war ruminants near the village of Mortka, to the east of Darbandikhan Lake in 2009 (Nature Iraq, 2017). Regardless, the status of Persian leopard in the mountains of northern Iraq was enigmatic and no sightings of live leopards have been made until a male leopard was captured by a camera trap in Qara Dahg area in Sulymaniyah Province in October 2011(Raza et al., 2012). In 2001-2014, 10 confirmed records of Persian leopard from northern Iraq and southeastern Turkey were investigated and hypothesized as a long dispersal of males from the Iranian populations (Avgan et al., 2016). It is also suggested 
that unnoticed isolated breeding populations may occur along the northwestern part of Zagros Mountains in northern Iraq and Western Iran (Avgan et al., 2016; Spassov et al., 2016). However, recent surveys reported the occurrence of Persian leopard in Barzan Area and Gali Balnda, and in Assos and Qara Dagh mountains (Nature Iraq, 2017).Furthermore, our interviews with local peoples near Bamo Mountain have reliably indicated that Persian leopards were seen very often and had been killed several times by local poachers, but no photographic evidences were obtained. In addition a Persian leopard was recently recorded in Bamo Mountain by a local photographer about $3 \mathrm{Km}$ far away from our camera trap site in 5 of October 2019.

This recent observation might be indicative of the same individual captured by our camera trap or may be of a different individual (Pl. 2). The distribution of Persian leopard in Bamo Mountain could be attributed to an expansion of the home range of some individuals that previously reported from Qara Dagh Mountain (e.g. Raza et al., 2012) or from the western Iranian populations (e.g. Moqanaki et al., 2013; Parchizadeh and Adibi, 2019; Farhadinia et al., 2019). It is very important to conduct further surveys to find out the exact numbers and population size of the Persian leopards in Bamo Mountain and adjacent areas. Based on the aforementioned, our recent sighting of Persian leopard for the first time in this Bamo Mountain is crucial; it will be a gate for further monitoring which will aid its conservation strategies.

The wild goat is another flagship bovid species recorded by our current survey; it is listed as Near Threatened (Weinberg and Ambarli, 2020). Scattered populations were recorded from 31 sites mainly distributed in northern Iraq (Kurdistan) and a new distribution range was recently discovered in eastern and southeastern Iraq. However, the actual zoogeographic distribution of the species and population trends are enigmatic (Al Sheikhly et al., 2020). In addition, during our field survey, we abundantly recorded 23 different individuals of wild goats in a period of 30 minutes, and a large numbered population was presumed to be existing in Bamo Mountain, a claim which additional surveys could confirm. Recording wild goats for the first time in Bamo Mountain is significant to delineate the zoogeographical distribution range of this species in northern Iraq, which would be supportive to further conservation actions.

Our recent surveys did not confirm the concurrence of other key carnivore species especially the Grey wolves, Brown bears, Jungle and wild cats, or Eurasian lynx which could be attributed to the low number of camera trap used in the survey and scarcity of other logistic and survey efforts. Nevertheless, our intensive interviews indicated that the presence of other mammalian species such as striped hyena, Middle Eastern badger, and other musteilds species was suspected and needed further investigations.

\section{Threats on the wild mammal fauna in Bamo Mountain}

Poaching and Wildlife trafficking:

In Bamo Mountain, wild mammals are threatened by extensive poaching. Some hunters are determined to killing wild mammals wherever possible. The movement of anonymous hunters was captured by our camera, a situation which indicates that our area seems to hosting illegal hunting activities (Pl. 3). In a related case, some of them have had stolen our camera trap in spite of being labeled as "for scientific work". Hunters easily reach all spots in Bamo 
Mountain using motorcycles mainly on military roads and trails created during Iraq-Iran war. Also, new roads were constructed by previous oil companies between minefields which became easy ways for hunters to reach the site.

Our interviews indicated that wild goats, Indian crested porcupines, badgers, wild hares, and squirrels are hunted and trapped continuously. The young of Persian squirrels are collected to be sold as pets in the local animals markets or transported to other Iraqi provinces for the same reason (e.g. Al-Sheikhly et al., 2015). The excessive hunting will possibly contribute to decreasing the pray abundance that sustain the Persian leopards and other coexisting predator populations in Bamo Mountain. Although the hunting of these mammalian species was banned by the Kurdistan Regional Government in 2015; however, the weak enforcement allows hunters to follow their illegal searches.

\section{Minefields:}

The existing of the minefields as remnants form Iraq-Iran 1980s war which and many still active and not cleared yet is one of the major threats on wildlife of northern Iraq (Nature Iraq and Iraqi Ministry of Environment, 2011). In a related occasion, the minefields were assigned as a direct impact on Persian leopard population in northeastern Iraq. A Persian leopard was killed by a landmine near the village of Mortka, to the east of Darbandikhan Lake in2009 (Nature Iraq, 2017). Therefore, based on our results, further minfields clearance activities should be conducted in and around the Bamo Mountain area.

\section{Annual Fires:}

Annual fires of the mountainous forests habitats have been assigned to have a direct impact on the wild mammals fauna and their habitats of Bamo Mountain particularly between late of June to end of October. It may cause direct mortalities, habitat destruction and fragmentation, anthropogenic disturbance, or it may contribute to being as a "pushing factor" which may remove or translocation of existing populations into a different distribution range (Pl. 4). The ignition source of the forests firing is not fully known. Besides natural causes such as drought and sever climate, anthropogenic influences could contribute to the forests annual firing in Bamo Mountain. Our interviews indicated that some local hunters are deliberately igniting fires in order to flash wild game such as wild goats or other bird species, or to smoking the wild honey bees away from their hives to facilitate honey extraction. In both cases, fires become uncontrolled and expand into wider ranges causing direct damage to the natural habitats of Bamo Mountain. In addition, mine explosion during dry season also may contribute to such occurrences. The causes of the mountainous forests firing are still not fully known and require further investigations.

As a concluding remark, for conservation concern, we suggest that a full closing of the main suburban off roads leading to Bamo Mountain, advocating and raising awareness among local communities towards the importance of the native wild flora and fauna, activating the forestry police offices, and controlling the annual fire are ideal ways to conserve the wildlife of Bamo Mountain. We have the best contact with local peoples; the majority of them show mindful support designating the site as protected areas for flora and fauna. Finally, conservation plans and environmental management are necessary for the protection of wildlife on Bamo Mountain to ensure the remaining of these unique wild mammals diversity. In addition, further systematic field surveys are also necessary to be implemented in this area 


\section{Ahmed and Majeed}

to determine the entire diversity and status of wild mammals and other fauna and flora species such as birds, reptiles, and native plants.

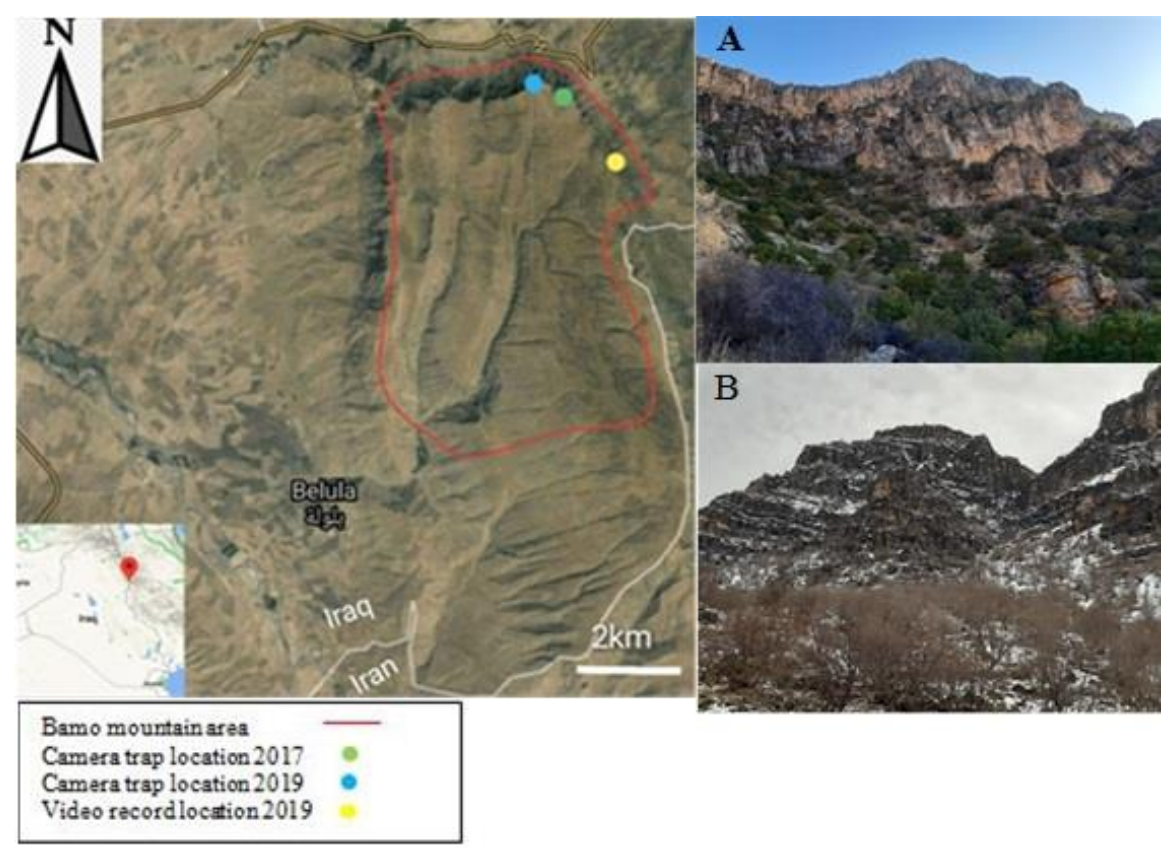

Map (1): A map of Bamo Mountain area (Extracted from Google Earth Software) with general landscape, seasonal vegetation and climate; (A) In summer, (B) In winter (Photos by Soran H. Ahmad). 

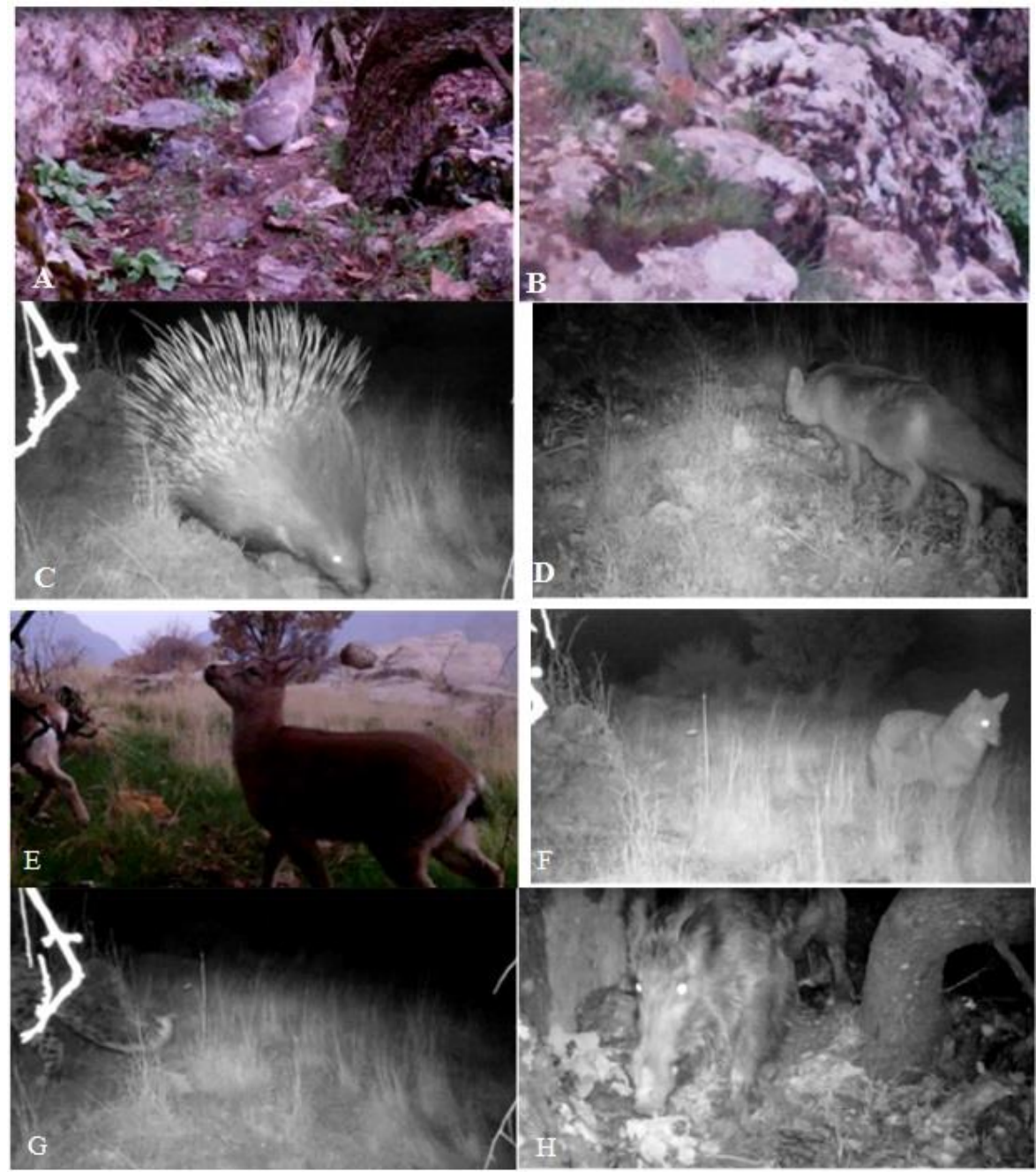

Plate (1): The mammal species recorded during camera trap survey in Bamo Mountain in northern Iraq (Kurdistan); (A) European hare Lepus (Eulagos) europaeus, (B) Caucasian squirrel Sciurus (Tenes) anomalus, (C) Indian crested porcupine Hystrix indica, (D) Red fox Vulpus vulpus, (E) Wild goat Capra aegagrus, (F) Golden jackal Canis aureus, (G) Persian leopard Panthera pardus saxicolor, (H) Wild boar Sus scrofa. (These photos are extracted from video records captured by our camera trap). 


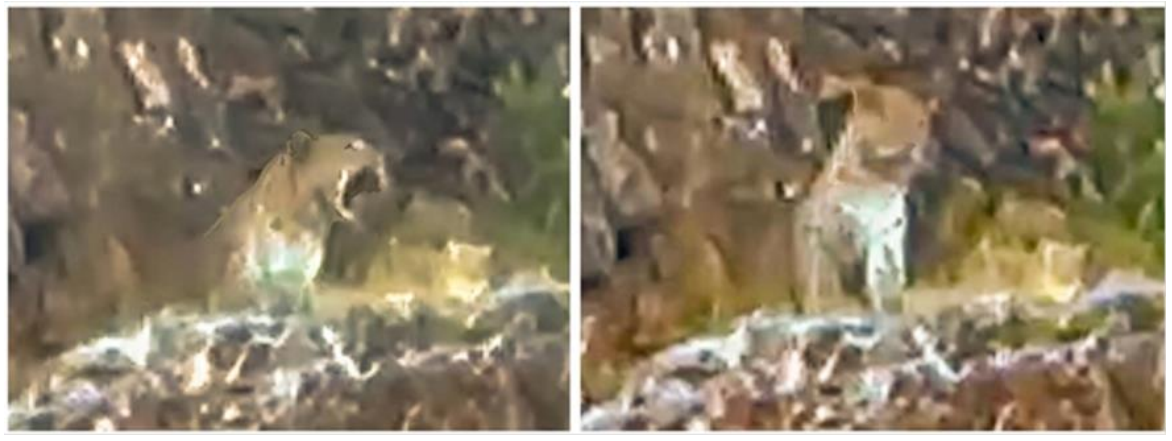

Plate (2): The Persian leopard Panthera pardus saxicolor, a key flagship species recorded in Bamo Mountain in northern Iraq in 2020 (rare photos extracted from a video footage taken by Khalid Sdiq Ahmed).

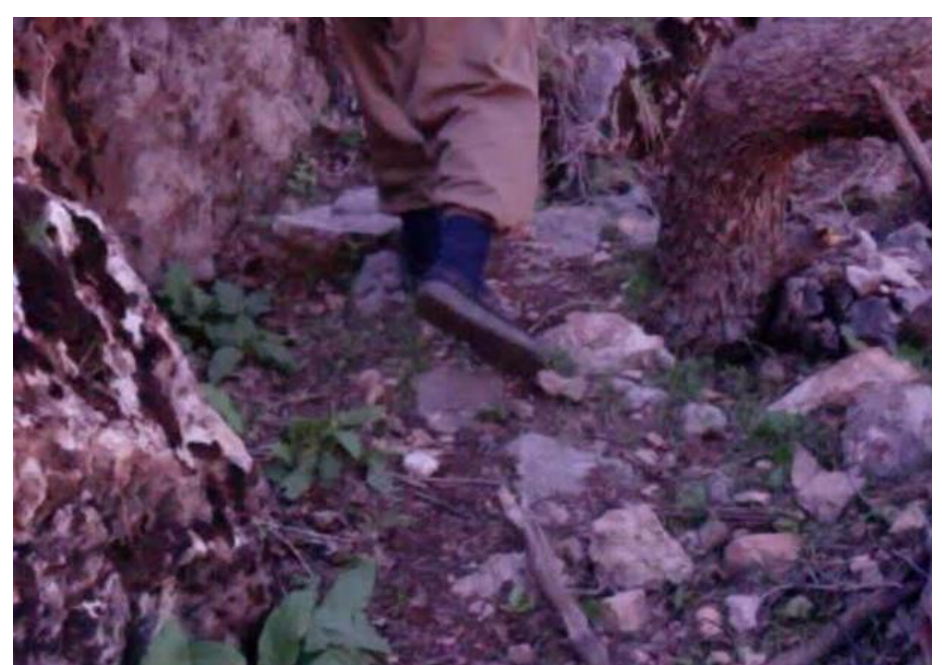

Plate (3): A local hunter in our camera trap trail. (anonymity is preserved with the authors).
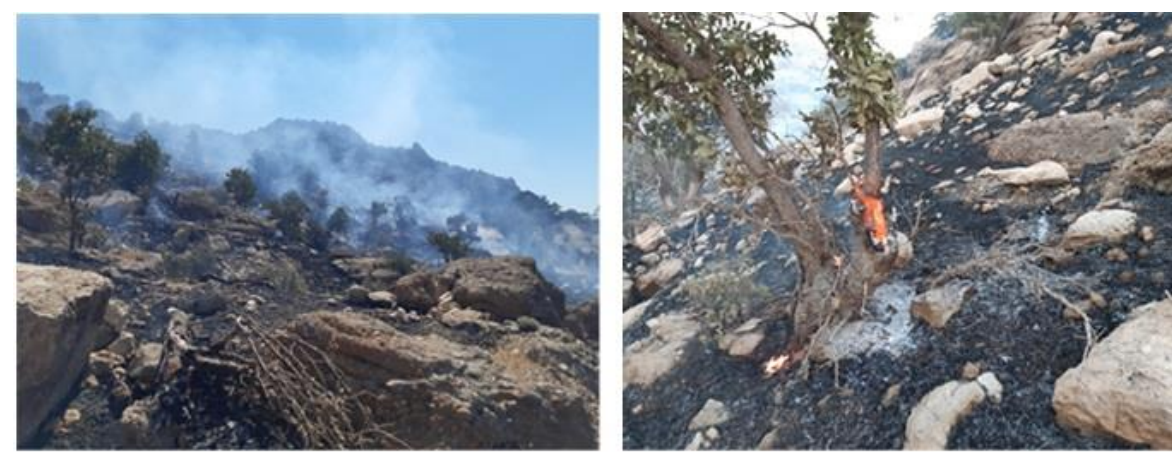

Plate (4): Bamo Mountain during fire.

(Photos by Soran H. Ahmed) 


\section{AKNOWLEDGMENTS}

We are glad to express our deepest gratitude to Omar F. Al-Sheikhly (University of Baghdad), Korsh Ararat (University of Sulaimani) and Hana Raza (Nature Iraq Organization) for their kind help and advice during writing this article. We also express our gratitude to the Forestry Police for finding our camera trap and to Khalid Sdiq Ahmed for extracting Persian leopard photo from his video footage.

\section{LITERATURE CITED}

Al-Sheikhly, O. F. 2012.The hunting of endangered mammals in Iraq. Wildlife Middle East, 6: 10 .

Al-Sheikhly, O. F. and Haba, M. K. 2014. The field guide to the wild mammals of Iraq. University of Baghdad, Collage of Science for Women, $89 \mathrm{pp}$.

Al Sheikhly, O. F., Haba, M. K., Barbanera, F., Csorba, G. and Harrison, D. L. 2015. Checklist of the mammals of Iraq (Chordata: Mammalia). Bonn Zoological Bulletin, 64 (1):33-58.

Al-Sheikhly, O. F., Haba, M. K., Görföl, T. and Csorba, G. 2015. First evidences of the occurrence of two bat species for Iraq. Mammalia. DOI: 10.1515/mammalia-20140098.

Al-Sheikhly, O. F., Haba, M. K., Ali N. Al-Barazengy and Nadheer A. Faza'a. 2020. New distribution range of the vulnerable wild goat (Capra aegagrus Erxleben, 1777) (Artiodactyla: Bovidae) to the south of its known extant in Iraq, with notes on its conservation. Bonn Zoological Bulletin, 69(1): 105-110.

Avgan, B., Raza, H., Barzani, M. and Breitenmoser, U. 2016. Do recent leopard Panthera pardus records from northern Iraq and south-eastern Turkey reveal an unknown population nucleus in the region? Zoology in the Middle East, 62: 95-104.

Bowyer, R. T., Boyce, M. S., Goheen, J. R. and Rachlow, J. L. 2019. Conservation of the world's mammals: status, protected areas, community efforts, and hunting. Journal of Mammalogy, 100(3): 923-941.

Debata, S. and Swain, K. K. 2018. Estimating mammalian diversity and relative abundance using camera traps in a tropical deciduous forest of Kuldiha Wildlife Sanctuary, eastern India. Mammal Study, 43(1): 45-53.

Farhadinia, M. S., McClintock, B. T., Johnson, P. J., Behnoud, P., Hobeali, K., Moghadas, P., Hunter, L. T. B. and Macdonald, D. W. 2019. A paradox of local abundance amidst regional rarity: the value of montanerefugia for Persian leopard conservation. Scientific Reports, 9(1): 1-12.

Harrison, D. L. and Bates, P. J. J. 1991. The mammals of Arabia, second edition. Harrison Zoological Museum, Sevenoaks, Kent, United Kingdom, 354 pp. 
Hatt, R. T. 1959. The mammals of Iraq. Miscellaneous Publications, Museum of Zoology, University of Michigan, no. 106, 113 pp.

Khorozyan, I. 2016. Panthera pardus ssp. saxicolor. The IUCN Red List of Threatened Species 2016: e.T15961A6947473. Downloaded on 02 September 2020.

Moqanaki, E., Breitenmoser, U., Kiabi, B. H., Masoud, M. and Bensch, S. 2013. Persian leopards in the Iranian Caucasus: a sinking 'source' population? Cat News, 59: 2225.

Nature Iraq and Iraqi Ministry of Environment. 2011. Key Biodiversity Areas of Iraq 2010 Site Review. Sulaimani: Nature Iraq. Publication No.NI-0311-01.

Nature Iraq. 2017. Key Biodiversity Areas of Iraq. Al-Ghadeer Printing, Basra, 297 pp.

Parchizadeh, J. and Adibi, M. A. 2019. Distribution and human-caused mortality of Persian leopards Panthera pardus saxicolor in Iran, based on unpublished data and Farsi gray literature. Ecology and Evolution, 9: 11972-11978.

Raza, H. A., Ahmad, S. A., Hassan, N. A., Ararat, K. and Mariwan, Q. 2012.First photographic record of the persian leopard in Kurdistan, northern Iraq. Cat News, 56: 34-35.

Spassov, N., Ignatov, A. and Acosta-Pankov, I. 2016. On the status of the leopard in Turkey, again. CAT News, 64:18-22.

Stein, A. B., Athreya, V., Gerngross, P., Balme, G., Henschel, P., Karanth, U., Miquelle, D., Rostro-Garcia, S., Kamler, J. F., Laguardia, A., Khorozyan, I. and Ghoddousi, A. 2020. Panthera pardus (amended version of 2019 assessment). The IUCN Red List of Threatened Species 2020: e.T15954A163991139. https://dx.doi.org/10.2305/IUCN.UK.2020-1.RLTS.T15954A163991139.en. Downloaded on 09 July 2020.

Sutherland, W. 2006. Ecological census techniques: a handbook. Cambridge University Press, Cambridge, 432 pp.

Weinberg, P. and Ambarli, H. 2020. Capra aegagrus. The IUCN Red List of Threatened Species 2020: e.T3786A22145942. https://dx.doi.org/10.2305/IUCN.UK.20202.RLTS.T3786A22145942.en. Downloaded on 07 September 2020.

Yasuda, M. 2004. Monitoring diversity and abundance of mammals with camera traps: a case study on Mount Tsukuba, central Japan. Mammal Study, 29(1): 37- 46. 


\section{مراقبة فونا الثييات البرية في جبل بامو في شمال العراق (كوردستان) لأول

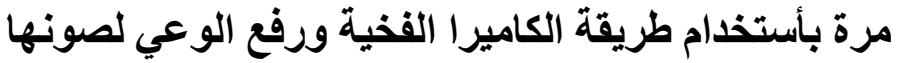

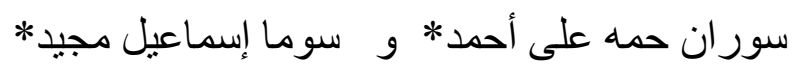 \\ *قسم علوم الحياة، كلية العلوم،جامعة السليمانية، السليمانية، العراق اق إن}

$$
\text { تأريخ الاستلام: 2020/07/21، تأريخ القبول: 2020/09/19، تاريخ النشر: 2020/12/21 }
$$

$$
\text { الخلاصة }
$$

تتعرض الثدييات البرية في جميع أنحاء العالم للتهديد نتيجة لأز الة الغابات, الصيد, وبسبب الفعاليات البشرية الأخرى. اذ سجل 93 نوعا من النهاء الثدييات

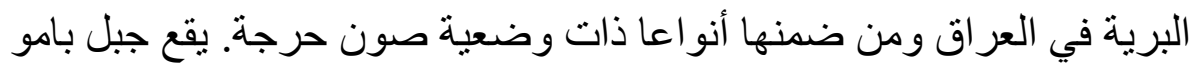
ضمن جبال ز اكروس في شمال العر اق و هو بيئة ملائمة للثنييات البرية. نتيجة لثحة المسوحات الحقلية والسلوك الخفي, تبدو مر اقبة الثنييات البرية في جبال ز اكروس من اهم التحديات؛ لذلك أستخدام الكاميرا الفخية لدر استها. 